Research Article

\title{
Effect of Yoganidra on Blood Pressure, Hs-CRP, and Lipid Profile of Hypertensive Subjects: A Pilot Study
}

\author{
J. P. Devraj $\mathbb{D}^{1},{ }^{1}$ B. Santosh Kumar $\mathbb{D}^{\circ},{ }^{2}$ M. Raja Sriswan ${ }^{1},{ }^{1}$ B. Jagdish, ${ }^{3}$ B. S. Priya, \\ S. B. Neelu, ${ }^{4}$ Vijayabhaskar Desai Rao, ${ }^{5}$ Manoj Kumar, ${ }^{6}$ J. J. Babu Geddam, ${ }^{1}$ \\ and R. Hemalatha ${ }^{4}$ \\ ${ }^{1}$ Division of Clinical Epidemiology, ICMR-National Institute of Nutrition, Hyderabad, Telangana-500 007, India \\ ${ }^{2}$ Clinical Division, ICMR-National Institute of Nutrition, Hyderabad, Telangana-500 007, India \\ ${ }^{3}$ Behavioral Science Unit, Extension \& Training Division, (ICMR)-National Institute of Nutrition, Hyderabad, \\ Telangana-500 007, India \\ ${ }^{4}$ ICMR- National Institute of Nutrition, Hyderabad, Telangana-500 007, India \\ ${ }^{5}$ Department of Biostatistics, (ICMR)-National Institute of Nutrition, Hyderabad, Telangana-500 007, India \\ ${ }^{6}$ Department of Microbiology, ICMR-National Institute of Research in Environmental Health, Bhopal, \\ Madhya Pradesh-462030, India
}

Correspondence should be addressed to B. Santosh Kumar; drsantoshkumar999@gmail.com and M. Raja Sriswan; srishwan@gmail.com

Received 7 July 2020; Revised 28 August 2021; Accepted 3 December 2021; Published 30 December 2021

Academic Editor: Robson Xavier Faria

Copyright (c) 2021 J. P. Devraj et al. This is an open access article distributed under the Creative Commons Attribution License, which permits unrestricted use, distribution, and reproduction in any medium, provided the original work is properly cited.

\begin{abstract}
Background. Yoganidra is a systematic method of promoting a state of complete physical, mental, and emotional relaxation. It is a safe, inexpensive, and very effective method of management of hypertension when used along with standard pharmacological therapy. This study aims to assess the effect of yoganidra on blood pressure (both systolic blood pressure (SBP) and diastolic blood pressure (DBP)), Hs-CRP, and lipid profile of hypertensive subjects at the time of enrollment (subjects that are hypertensive at the time of enrollment). Methods. Both treated and untreated subjects $(n=74)$ with hypertension (blood pressure $\geq 140 / 90 \mathrm{mmHg}$ ) and age between 35 and 70 years were included in this study after obtaining ICMR-NIN-IEC approval and written informed consent from all subjects. Subjects with critical illness and/or psychological disturbances were excluded from this study. The subjects in the experimental group $(n=31)$ practiced yoganidra for 45 minutes daily for 12 weeks under strict supervision. There was no intervention in the control group $(n=43)$. Weekly blood pressure was recorded in the experimental group, whereas it was performed at baseline and at endpoint for control groups. Hs-CRP and lipid profile were estimated at baseline and endpoint for both the groups. Results. A significant reduction in mean SBP from $142.9 \mathrm{~mm} \mathrm{Hg}(\mathrm{SD} \pm 16.46)$ to $118.68 \mathrm{~mm} \mathrm{Hg}(\mathrm{SD} \pm 9.21$; $p$ value 0.0001$)$ and $\mathrm{DBP}$ from $89.84 \mathrm{~mm} \mathrm{Hg}(\mathrm{SD} \pm 10.42)$ to $77.03 \mathrm{~mm} \mathrm{Hg}$ ( $\mathrm{SD} \pm 6.47$ : $p$ value 0.0001 ) was observed among the experimental group after 12 weeks of yoganidra practice when compared with the control group. A significant reduction in mean Hs-CRP $(2.21 \pm 1.49$ to $1.06 \pm 0.82 \mathrm{mg} / \mathrm{L}$, $\left.p<0.001^{* * *}\right)$ was observed among the experimental group. There were no significant differences between triglycerides and total cholesterol levels, whereas LDL-C and HDL-C showed a trend of improvement in the experimental group after intervention. Conclusions. In this pilot study, we observed a significant reduction in blood pressure and Hs-CRP in the yoganidra group compared with the control group. There were no significant side effects observed in the intervention group during the study period.
\end{abstract}

\section{Introduction}

Hypertension (HTN) is a significant public health problem, which affects the cardiovascular health of most of the people in India. According to the World Health Organization [1],
$140 / 90 \mathrm{~mm} \mathrm{Hg}$ or higher is considered hypertension. By 2025 , there will be 1.56 billion adults who may become hypertensive, as globally estimated. Nearly 8 million and 1.5 million people will die every year worldwide and in the South-East Asia (SEA) region [1], respectively. The 
prevalence of hypertension in India is seen to be increasing day by day. One among the three adults is reported to be hypertensive in a recently shown national-level survey. It was conducted with a fixed one-day blood pressure measurement of 180,335 participants through camps across more than 20 states of India. A study reported that the prevalence of hypertension was $30.7 \%$ [2]. A recent "Global Burden of Disease" study reported that hypertension led to India's 1.63 million deaths in 2016 alone. It was the second leading risk factor in terms of attributable disability-adjusted life years (DALYs) in men (122.2 million DALYs) after smoking and the leading risk factor in women (89.9 million DALYs) [3]. Nevertheless, about $25.6 \%$ of subjects on medication had their B.P. under normal levels. More than $50 \%$ of all stroke deaths and $24 \%$ of all coronary heart disease deaths in India are due to raised blood pressure [4]. Longterm high blood pressure leads to coronary artery disease, stroke, heart failure, atrial fibrillation, peripheral vascular disease, vision loss, chronic kidney disease, and dementia $[5,6]$. Thus, the burden of hypertension can be genuinely considered as a pandemic. It has been found that dyslipidemia, inflammation, stress, high-risk behaviors, and sedentary and unhealthy lifestyles are significant causes of hypertension. Dyslipidemia is recognized as a prominent risk factor for CVD [7]. Altered lipid parameters, low HDL levels, raised LDL-C, and triglycerides are associated with a rise in cardiovascular diseases. Hs-CRP is an acute-phase reactant synthesized by the liver and elevated in response to acute infections, inflammatory conditions, and trauma [8]. Several studies have shown that serum Hs-CRP can be an excellent diagnostic and a prognostic marker in diagnosing prehypertensive subjects, and elevated levels have shown a greater risk of stroke and cardiovascular disorders [9-11]. Antihypertensive medications are essential in the management of hypertension. Major antihypertensive agents used are ACE inhibitors, diuretics, $\beta$-blockers, angiotensin II receptor blockers, calcium channel blockers, and vasodilators. Due to the side effects of these medications, nonadherence occurs in about $50 \%$ of newly treated hypertensive patients within the first year of treatment [12-15]. Long-term use of antihypertensive drugs has a significant risk of developing type 2 diabetes, osteoporotic fractures, atrial fibrillation, and breast cancer in women [16-18]. Over the years, patients with hypertension may experience mental health disorders such as anxiety, depression, and stress, which again lead to increased blood pressure [19]. Long-term use of medications leads to decreased quality of life [20]. All these constitute a significant burden on the economy of the country. Several studies have been conducted on diet and physical activity to reduce blood pressure in hypertensive subjects [21, 22]. Although these have been mainly beneficial, they tend to be effective as long as a given regimen is followed. Often people find it challenging to incorporate specific lifestyle changes. It is observed that yoganidra, when used along with standard therapy, is a safe, inexpensive, and very effective method of management of hypertension [23-26]. Yoganidra has been used earlier as a therapeutic option with no documented side effects. Previous studies have separately reported the effect of yoganidra on hypertension, $\mathrm{Hs}-\mathrm{CRP}$, and lipid profile [23-26]. In this study, we have assessed all the three parameters (reduction in blood pressure, Hs-CRP, and lipid profile) in one study among hypertensive subjects on pilot mode.

\section{Methodology}

2.1. Sample Size and Study Subjects. Since this study was planned to be a pilot one, we have not calculated the sample size for this study. The nonprobability convenient sampling technique was adopted to select the subjects for this study. Subject recruitment was performed based on the inclusion and exclusion criteria listed below.

2.2. Inclusion and Exclusion Criteria. Subjects (on medication/without medication) aged between 35 and 70 years old having blood pressure $\geq 140 / 90 \mathrm{mmHg}$ were screened. Subjects who were pregnant and lactating, those who were with critical illness and hearing impairment, or those taking any kind of sedatives or psychological treatments were excluded from this study. Seventy-four eligible subjects with HTN were recruited after obtaining NIN-IEC approval (IEC no. 04/II/2016) and written informed consent. Data on anthropometry such as height, weight, sociodemographic details such as education, professional clinical history regarding the onset and duration of hypertension, family history, and duration of drug therapy, type, and dosage of drugs was obtained. The experimental (or test) group included subjects who could comprehend the relaxation techniques, showed interest in yoganidra, and could commit to attending and regularly practicing yoganidra as per our recommendation. Others were included in the control group and were asked to continue with a regular diet, physical activity, and medications prescribed by physicians. Blood samples $(5 \mathrm{ml})$ were collected for Hs-CRP and blood lipid profile for all recruited subjects at baseline and endpoint (after 12 weeks). In the intervention group, thirty-one hypertensive subjects on medication $(n=19)$ and no medication $(n=12)$ were included to practice yoganidra daily $(45 \mathrm{~min} / \mathrm{d})$ for 12 weeks, at institute premises under the guidance of a trained yoga instructor. During the study duration, blood pressure was monitored weekly by the physician before the yoganidra session-using both manual and digital B.P. apparatus. The subjects were asked to relax for $10 \mathrm{~min}$ before the start of yoganidra to decrease or minimize the white-collar effect.

2.3. Blood Pressure and Data Collection. Our main aim was to assess the impact of yoganidra on blood pressure in the intervention group and evaluate its effect on a weekly basis. We included the control group to compare their blood pressure at two time points with the intervention group. Blood pressure was measured in the sitting position before starting yoganidra every week for 12 weeks for all subjects in the experimental group using a digital blood pressure monitor (oscillatory-OMRON) and mercury sphygmomanometer (auscultatory). Each subject was asked to relax in a 
sitting posture for $5 \mathrm{~min}$. Three readings of digital blood pressure monitor and one reading of mercury sphygmomanometer were taken to ensure accuracy. The first reading of blood pressure was measured using a digital blood pressure monitor. Two more readings were recorded by maintaining an interval of 5 minutes. The fourth reading was taken using a mercury sphygmomanometer. All readings were duly recorded.

2.4. MAP. Mean arterial pressure (MAP) is the average blood pressure in an individual during a single cardiac cycle. It is calculated by using the following formula $\mathrm{MAP}=\mathrm{SBP}+2 \mathrm{DBP} / 3$. MAP value of $70-100$ is considered to be normal. Any variations, which are high or low, are a sign of the underlying medical disorder.

2.5. Control Group. Forty-two hypertensive subjects with or without medication were included in a control group without any lifestyle modification. One subject was excluded due to noncompliance. Both male and female subjects were included with disease duration ranging from 1 to 15 years.

2.6. Intervention Group. The yoganidra intervention was conducted at the institute premises in a semidark room from 5:30 pm to 6:30 pm for 5 days in a week for 12 weeks. The subjects were strictly monitored, and an attendance register was maintained to check the regularity of the subjects. Then, subjects were asked to do warm-up exercises like body rotation and joint rotation after a 2-3 min brisk walk to get them ready for yoganidra intervention. These warm-up steps help subjects to be active, attentive, and energetic during the intervention period. Otherwise, there is a possibility of subjects going into deep sleep. Then, subjects were asked to lay in shavasana (relaxed lying down on the back) position for yoganidra protocol ( $35 \mathrm{~min})$ in the semidark room, under the supervision of the yoga instructor and an investigator. The room was provided with an audio CD player and speakers. Since darkness and light have an effect on the brain, semidarkness is necessary to maintain a state of relaxed awareness to maintain a balance between introversion and extroversion.

2.7. The Technique of Yoganidra. Yoganidra means sleeping consciously, which systematically induces complete physical, mental, and emotional relaxation [26]. Yoganidra has a preventive, promotive, and curative value. It is a noninvasive, easy-to-practice, cost-effective intervention to prevent stress [24]. Yoganidra is a meditation and relaxation technique that focuses more on the mind than on the physical body. Its mode of principal action on the mind may bring down sympathetic activity and reduce blood pressure [24].

2.8. Stages of Yoganidra. The practice of yoganidra was performed in the following stages: in the preparatory stage, body and mind were wholly relaxed by inducing the awareness of stillness and comfort of the body by correcting posture and position, speed of breath, and listening to the external sounds. The subjects were educated to be aware of the surroundings and asked them to be in the state of witnessing the activity. In the second stage, subjects were instructed to take sankalpa or a resolution according to their wish after the body and mind were completely relaxed. They were told to keep it short, clear, and positive and were asked to mentally repeat the selected sankalpa three times, with full determination, conviction, and confidence. During the third stage, consciousness or awareness was systematically switched throughout the different parts of the body. Subjects were instructed to remain aware, listen to the instructions, and very rapidly move the mind according to the instructions without making any physical movements. A definite sequence was followed to shift the awareness. In the next stage, subjects were asked to become conscious of the natural breath without changing the breath flow. Subjects were aware of each inspiration and expiration by mentally counting them. During the 5th stage, the physical or emotional sensations were recalled, intensified, and fully experienced. Pairs of contradictory feelings or sensations were practiced by asking subjects to imagine the heat and cold, heaviness and lightness, pain and pleasure, love and hate, and so on. In the visualization stage, the subjects were asked to visualize some objects, stories, or situations in the chidakasha ("space of consciousness" or "inner space.") At this time once again, subjects were asked to mentally repeat sankalpa three times, which was taken earlier in stage two, with full dedication, faith, and optimism. In the final stage, slowly, the awareness was externalized by asking the subjects to become aware of the external sounds, objects, and persons. They were then asked to slowly move the body parts and to stretch the body. We observed that initially, for 3-5 days, most of the subjects fell asleep for 5-10 min. It was difficult for them to remain awakened during yoganidra. After five days, they got used to the practice of yoganidra.

2.9. Quality Control. As the first step, midupper arm circumference was measured to use an accurate cuff bladder size to obtain accurate blood pressure. Quality control for measuring blood pressure was ensured, which includes two parts, the checking of equipment and performance monitoring of the blood pressure recorders. Before checking the first blood pressure measurement, we checked to ensure that the sphygmomanometer's mercury column was at zero and the mercury column smoothly falls when the cuff was deflated. We also checked whether the column properly latches into the vertical position. The results were recorded in a book. The following precautions were taken for the correct measurement of blood pressure: an average of three readings was taken at intervals of $5 \mathrm{~min}$. The subjects were allowed to sit for at least $10 \mathrm{~min}$ in a quiet room before taking blood pressure measurement.

Blood pressure measurement was performed in a standard sitting position. The subject's arm was fully bared and supported at the level of the heart. The blood pressure recordings were taken as mentioned in the intervention group. These readings were taken as pretrial blood pressure 
measurements. The controls were selected from our institute's clinic, and 62 subjects were screened, out of which, 43 subjects were selected based on inclusion and exclusion criteria. In this group, 30 men and 13 women were included with hypertension duration ranging from 1 to 20 years with a mean of 5.02 years. Thirty-four were on antihypertensive drugs, and the remaining subjects were newly diagnosed, who are on diet and lifestyle modification. All the recruited subjects were asked not to change their drug and dosage during the study period. None practiced yoganidra earlier, both among the intervention and the control group.

2.10. Biochemical Parameters. Five $\mathrm{ml}$ blood samples were collected (twice) from all recruited subjects in the morning after an overnight fast of 12 hours to assess the effect of yoganidra on Hs-CRP and blood lipid profile.

2.11. Hs-CRP. Hs-CRP was measured by immunoturbidimetry. It was classified according to the recommendation of the American Heart Association and Center for Disease Control, defining Hs-CRP $<1 \mathrm{mg} / \mathrm{L}$ as low risk, between 1 and $3 \mathrm{mg} / \mathrm{L}$ as moderate risk, and $>3 \mathrm{mg} / \mathrm{L}$ as high risk [27].

2.12. Lipid Profile. Total cholesterol and triglyceride concentrations were determined by enzymatic methods. HDL-C was determined following the deletion of triglyceride-rich lipoprotein and low-density lipoprotein (LDL-C) using the HDL direct liquid select TM kit. LDL cholesterol was calculated using Friedewald's formula: LDL-C $=$ TC-HDL minus (TG/5) [28].

2.13. Statistical Analysis. Descriptive statistics was performed employing the SPSS-20 version for variables with a normal distribution.

Descriptive values were expressed as means and standard deviations. In this study, $p<0.05$ was considered to be the level of significance. The proportions of responders and nonresponders to yoganidra were compared among treated/on medication and untreated/no medication groups by percentage.

\section{Results}

Both treated and untreated subjects (74) with hypertension were recruited and were grouped into the experimental $(n=31)$ and control group $(n=43)$. Anthropometry and sociodemographic details are as shown in Table 1. Male subjects were more among both the groups $(77 \%$ in the experimental and $70 \%$ in the control group). The mean age of study subjects in the experimental group was 54.61 years $(\mathrm{SD} \pm 9.95)$ and the control group was 49.64 years $(S D \pm 7.67)$. More than $95 \%$ of subjects were aged more than 45 years in the experiment, whereas it was $80 \%$ among the control group. About $90 \%$ of subjects were literate up to intermediate level and above among both the groups. Less than $10 \%$ had a temporary job, and $10 \%$ were unemployed. The remaining subjects were either government employees or were engaged in business among the experimental group, whereas $14 \%$ were unemployed and $21 \%$ had temporary jobs
TABLE 1: Comparision of demographic details among both groups.

\begin{tabular}{lcc}
\hline & Experimental $(n=31)$ & Control $(n=43)$ \\
\hline Male $(n+\%)$ & $24(77.4)$ & $30(69.8)$ \\
Female $(n+\%)$ & $7(22.6)$ & $13(30.2)$ \\
Age $($ mean \pm SD) & $54.61 \pm 9.95$ & $49.645 \pm 7.67$ \\
$35-44(n+\%)$ & $1(3.2)$ & $9(20.93)$ \\
$45-54(n+\%)$ & $7(22.6)$ & $21(48.83)$ \\
$55-65(n+\%)$ & $10(32.3)$ & $11(25.58)$ \\
$>65(n+\%)$ & $13(41.9)$ & $2(4.65)$ \\
Illiterate $(n+\%)$ & $1(3.2)$ & $4(9.3)$ \\
Up to inter $(n+\%)$ & $7(22.6)$ & $21(48.8)$ \\
Up to graduate $(n+\%)$ & $10(32.3)$ & $9(20.9)$ \\
PG and above $(n+\%)$ & $13(41.9)$ & $9(20.9)$ \\
Govt job & $12(38.7)$ & $18(41.9)$ \\
Pvt/temporary job & $3(9.7)$ & $9(20.9)$ \\
Business & $5(16.1)$ & $9(20.9)$ \\
Not earning & $3(9.7)$ & $6(14.0)$ \\
Retired personnel & $8(25.8)$ & $1(2.3)$ \\
HTN-T & $19(61.29)$ & $34(79.06)$ \\
HTN-U & $12(38.7)$ & $9(20.93)$ \\
\hline
\end{tabular}

among the control group. Comparisons of BMI, SBP, DBP, PR, MAP, Hs-CRP, and lipid profile are shown in Table 2. Significant reduction in mean SBP from $142.9 \mathrm{~mm} \mathrm{Hg}$ $(\mathrm{SD} \pm 16.46)$ to $118.68 \mathrm{~mm} \mathrm{Hg}(\mathrm{SD} \pm 9.21)$ ( $p$ value 0.0001$)$ was observed among the experimental group after 12 weeks of yoganidra intervention when compared with the control group (from baseline: $134.29 \mathrm{~mm} \mathrm{Hg}(\mathrm{SD} \pm 14.17)$ to endpoint: $130.71 \mathrm{~mm} \mathrm{Hg}(\mathrm{SD} \pm 16.21$ : $p$ value 0.114$)$ ). A significant reduction in DBP was observed among the experimental group from $89.84 \mathrm{~mm} \mathrm{Hg}(\mathrm{SD} \pm 10.42)$ to $77.03 \mathrm{~mm} \mathrm{Hg}(\mathrm{SD} \pm 6.47: p$ value 0.0001$)$ after 12 weeks of yoganidra practice when compared with the controls (baseline: $86.84 \mathrm{~mm} \mathrm{Hg}(\mathrm{SD} \pm 14.17)$ to endpoint $84.16 \mathrm{~mm}$ $\mathrm{Hg}(\mathrm{SD} \pm$ 9.82: $p$ value 0.121)). The mean difference and median of SBP were 24.22 and 23.00, whereas the mean difference and median of DBP were 12.8 and 14.0 after 12 weeks of the intervention of yoganidra among the experimental group. Since SBP and DBP were not matched at baseline, after adjusting for them, a highly significant reduction in SBP (mean $16 \mathrm{~mm} / \mathrm{Hg}$ ) and DBP (mean $8.6 \mathrm{~mm} /$ $\mathrm{Hg}$ ) was observed among the experimental group $\left(p<0.001^{* *}\right)$. Weekly blood pressure was recorded for experimental group subjects, and the mean and SD of both SBP and DBP were as shown in Figures 1(a) and 1(b). A gradual reduction in both SBP and DBP was observed among the intervention group. Furthermore, when the effect of yoganidra was compared among treated/on medication and untreated/no hypertensive medication subjects (Table 3), there were 19 subjects on standard pharmacological treatment, whereas 12 were newly diagnosed untreated cases in the experimental group. The mean difference of SBP among treated and untreated groups was 23.47 and $27.03 \mathrm{~mm} \mathrm{Hg}$ and DBP was 11.52 and $15.57 \mathrm{~mm} \mathrm{Hg}$, respectively. It was observed that the mean difference between SBP and DBP was more among the untreated group. Any intervention that reduces blood pressure by $10 \mathrm{~mm} \mathrm{Hg} \mathrm{SBP}$ and $5 \mathrm{~mm} \mathrm{Hg}$ DBP has good clinical significance [29]. We grouped among responders (SBP $>10 \mathrm{mmhg}$ and $\mathrm{DBP}>5 \mathrm{mmhg}$ ) and 
TABLE 2: Effect of yoganidra on blood pressure, Hs-CRP, and lipid profile among experimental and control group subjects.

\begin{tabular}{|c|c|c|c|c|c|c|c|c|c|}
\hline \multirow{2}{*}{ Sl. no. } & \multirow{2}{*}{ Parameters } & \multicolumn{4}{|c|}{ Experimental group $(n=31)$} & \multicolumn{4}{|c|}{ Control group $(n=43)$} \\
\hline & & Pre $($ mean $\pm S D)$ & Post $($ mean $\pm \mathrm{SD})$ & Mean diff & $p$ value & Pre $($ mean $\pm S D)$ & Post $($ mean $\pm S D)$ & Mean diff & $p$ value \\
\hline 1 & BMI & $28.68 \pm 3.91$ & $28.29 \pm 3.62$ & 0.389 & $0.009^{*}$ & $27.61 \pm 4.77$ & $27.58 \pm 4.95$ & 0.03 & 0.872 \\
\hline 2 & SBP & $142.9 \pm 16.46$ & $118.68 \pm 9.21$ & 24.22 & $0.0001^{* *}$ & $134.29 \pm 14.17$ & $130.71 \pm 16.21$ & 3.58 & 0.114 \\
\hline 3 & DBP & $89.84 \pm 10.42$ & $77.03 \pm 6.47$ & 12.8 & $0.0001^{* *}$ & $86.84 \pm 10.13$ & $84.16 \pm 9.82$ & 2.68 & 0.121 \\
\hline 4 & $\mathrm{PR}$ & $80.61 \pm 11.49$ & $78.94 \pm 9.05$ & 1.677 & 0.247 & $84.16 \pm 9.82$ & $81.19 \pm 11.73$ & -0.52 & 0.85 \\
\hline 5 & MAP & $107.61 \pm 11.07$ & $90.92 \pm 6.48$ & 16.69 & $0.0001^{* *}$ & $102.58 \pm 9.44$ & $99.75 \pm 11.23$ & 2.83 & 0.072 \\
\hline 6 & Hs-CRP & $2.21 \pm 1.49$ & $1.06 \pm 0.82$ & -1.15 & $0.0001^{* *}$ & $1.22 \pm 1.05$ & $2.57 \pm 1.71$ & 1.35 & $0.0001^{*}$ \\
\hline 7 & Trig & $155.84 \pm 195.56$ & $158.71 \pm 140.73$ & -2.87 & 0.858 & $131.24 \pm 74.28$ & $130.84 \pm 54.63$ & 0.4 & 0.971 \\
\hline 8 & Tot. Chol & $184.94 \pm 32.19$ & $186.00 \pm 33.65$ & -1.0645 & 0.806 & $175.04 \pm 37.46$ & $181.0 \pm 34.86$ & -5.96 & 0.147 \\
\hline 9 & HDL & $51.0 \pm 11.93$ & $53.97 \pm 14.04$ & -2.968 & 0.359 & $52.64 \pm 9.57$ & $51.73 \pm 12.50$ & 0.91 & 0.77 \\
\hline 10 & LDL & $95.83 \pm 29.64$ & $89.63 \pm 28.40$ & 6.2 & 0.297 & $92.76 \pm 28.96$ & $88.0 \pm 31.90$ & 4.76 & 0.384 \\
\hline 11 & VLDL & $31.17 \pm 39.11$ & $31.74 \pm 28.15$ & -0.574 & 0.858 & $26.25 \pm 14 . \pm 86$ & $26.17 \pm 10.93$ & 0.08 & 0.971 \\
\hline
\end{tabular}

SD, standard deviation. ${ }^{*}$ Significant and ${ }^{* *}$ highly significant $(p$ value $<0.005)$.

nonresponders. When the proportions of responders and nonresponders were compared (Table 4), which showed that SBP responders were $94.73 \%$ in the treated group and $83.33 \%$ responders were in an untreated group, whereas for DBP nonresponders were $79 \%$ in treated and $100 \%$ in the untreated group. MAP was compared from baseline to endpoint among both groups. A significant reduction in MAP $(107.76 \pm 11.07$ to $90.92 \pm 6.48$ : mean difference 16.69 $p$ values 0.0001 ) was observed among the experimental group, whereas reduction in MAP was not significant in the control group $(102.58 \pm 9.44$ to $99.75 \pm 11.23)$. When HsCRP was analyzed, a significant reduction in mean Hs-CRP $(2.21 \pm 1.49$ to $1.06 \pm 0.82 \mathrm{mg} / \mathrm{L} ; p<0.001)$ was observed among the experimental group after 12 weeks of a regular practice of yoganidra, whereas with a significantly increased mean Hs-CRP was observed among the control group $(1.22 \pm 1.05$ to $2.57 \pm 1.71 \mathrm{mg} / \mathrm{L} ; p<0.001)$. When the lipid profile was analyzed, it was found that there were no significant differences in triglycerides and total cholesterol levels among both groups, whereas HDL-C and LDL-C showed a trend of improvement without statistical significance in the experimental group after the intervention, which may be due to the small sample size.

\section{Discussion}

Hypertension is an important and common risk factor for cardiovascular diseases, stroke, diabetes, etc., which leads to considerable morbidity and mortality in developed and developing countries and is a pandemic problem. Hypertension and its ancillary complications globally are a leading cause of death in modern societies. The medications used in the management of hypertension not only decrease blood pressure but also cause some side effects [20] that lead to poor compliance. Prolonged usage of medications may cause the onset of chronic noncommunicable diseases, decreased quality of life, and work output, thus adding a major burden on the country's economy. Hypertension is a multifactorial disease, and its pathogenesis is not fully understood. In subjects with hypertension, arterial pressure is persistently high without any identifiable cause. It is mainly dependent on cardiac output and total peripheral resistance. The possible mechanisms are believed to be sympathetic nervous system overactivity and consequent increase in peripheral vascular resistance. Besides this, the sympathetic nervous system's direct pressure effect and catecholamine released from the adrenal medulla may also play a role. Hypertrophy of systemic arterioles could represent an adaptive response to chronically elevated blood pressure and perpetuate systemic hypertension. Inappropriately high sympathetic nervous outflow from the central nervous system is also believed to be an important component in the pathophysiology of acute and chronic essential hypertension, increasing cardiac output, and peripheral resistance [30].

Yoganidra centrally acts upon the brain to induce complete relaxation throughout the nervous system, and it improves the resistance levels of the physiological and physical systems of an individual. It controls the autonomic nervous system, influencing the brain's electrical rhythms, heart rate, and systolic and diastolic blood pressures. It maintains altered levels of circulating "stress hormones" including adrenaline and cortisol from the adrenal glands and decreased sympathetic nervous activity as reflected in increased galvanic skin resistance. In this pilot study, we used yoganidra as adjuvant therapy along with the standard medications. A significant reduction in SBP and DBP was observed after 12 weeks of supervised yoganidra practice in hypertensive subjects. Our observations are in line with earlier studies [23-25, 31-35]. Even though there was a gradual reduction in both SBP and DBP from baseline to endpoint. During the 4 th week to the 5 th week, there was a slight increase in both SBP and DBP, which was shown in Figures 1(a) and 1(b), which may be due to the fact that the subjects reduced their dose of antihypertensive drugs by $50 \%$. A significant reduction in SBP and DBP and a high response rate among the untreated (Tables 3 and 4) compared with the treated group suggests that yoganidra is very effective among untreated or newly diagnosed subjects with HTN. To confirm our observations and recommend yoganidra to hypertensive subjects, multicentric randomized controlled trials need to be planned. A significant reduction in MAP was observed among the yoganidra group compared with the control group, which is reported for the first time. It was normalized in our study subjects after 12 weeks of 


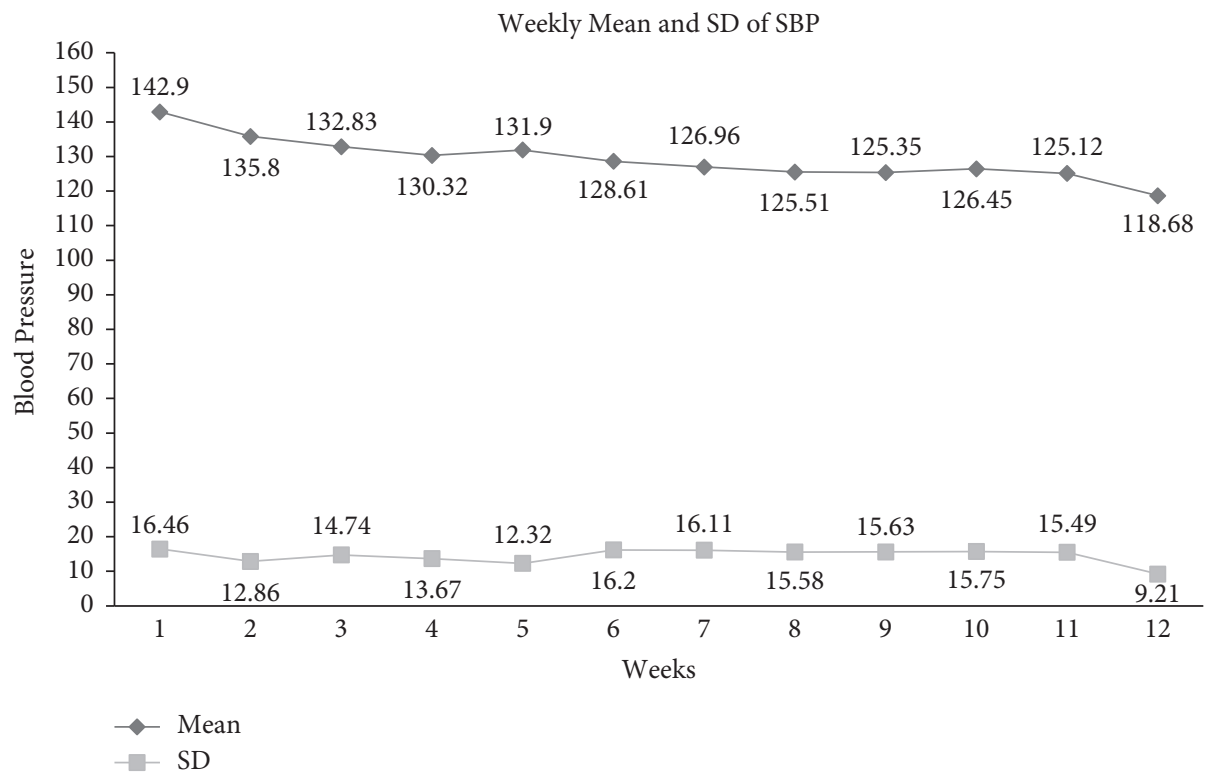

(a)

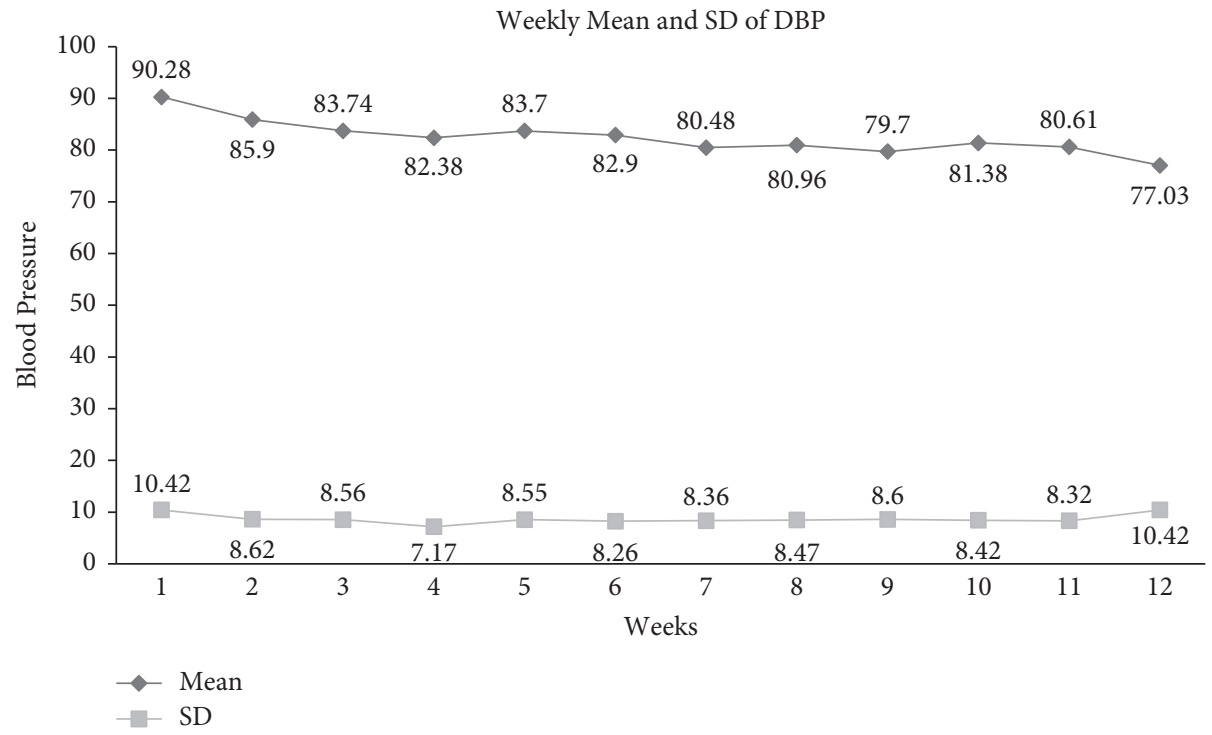

(b)

FIgURE 1: (a) Weekly mean and SD of SBP among the yoganidra-treated group and (b) weekly mean and SD of DBP among the yoganidra-treated group.

TABLE 3: Effect of yoganidra on blood pressure among untreated and treated cases.

\begin{tabular}{|c|c|c|c|c|c|c|c|}
\hline Sl. no. & Group & Parameters & Time points & $N+$ & Mean $( \pm S D)$ & Mean diff & Two-tailed $p$ value \\
\hline \multirow[t]{2}{*}{1} & Treated & SBP & Pre & 19 & $141.52(14.99)$ & 23.47 & $<0.001^{* *}$ \\
\hline & & & Post & 19 & $118.05(9.46)$ & & \\
\hline \multirow[t]{2}{*}{2} & Untreated & SBP & Pre & 13 & $146.69(19.12)$ & 27.03 & $<0.001^{* *}$ \\
\hline & & & Post & 12 & $119.66(9.09)$ & & \\
\hline \multirow[t]{2}{*}{3} & Treated & DBP & Pre & 19 & $86.94(11.11)$ & 11.52 & $0.001^{* *}$ \\
\hline & & & Post & 19 & $75.42(6.86)$ & & \\
\hline \multirow[t]{2}{*}{4} & Untreated & DBP & Pre & 13 & $95.15(7.67)$ & 15.57 & $0.004^{* *}$ \\
\hline & & & Post & 12 & $79.58(5.05)$ & & \\
\hline
\end{tabular}

SD, standard deviation. ${ }^{* *}$ Highly significant $(p$ value $<0.005)$. 
TABLE 4: Comparison of responders to yoganidra ( $\mathrm{SBP} \geq 10 \mathrm{~mm}$ hg and $\mathrm{DBP} \geq 5 \mathrm{~mm} \mathrm{hg}$ ) among treated and untreated cases.

\begin{tabular}{lccc}
\hline Sl. no. & Parameters & Treated group & Untreated group \\
\hline 1 & SBP responders $(\geq 10 \mathrm{~mm} \mathrm{hg})$ & $18 / 19(94.73 \%)$ & $10 / 12(83.33)$ \\
2 & SBP nonresponders $(<10 \mathrm{~mm} \mathrm{hg})$ & $1 / 19(5.26 \%)$ & $2 / 12(16.66)$ \\
3 & DBP responders $(\geq 5 \mathrm{~mm} \mathrm{hg})$ & $15 / 19(78.94 \%)$ & $12 / 12(100)$ \\
4 & DBP nonresponders $(<5 \mathrm{~mm} \mathrm{hg})$ & $4 / 19(21.05 \%)$ & 0 \\
\hline
\end{tabular}

yoganidra practice. Hs-CRP and erythrocyte sedimentation rate (ESR) are known as inflammatory markers with clinical significance among hypertensive subjects. In this study, a significant reduction in Hs-CRP levels among the intervention group was observed compared to the control group. There are no studies so far on the effect of yoganidra on HsCRP among hypertensive subjects. In contrast, the earlier study by Kumar and Pandya [35] suggested that yoganidra has the potential to reduce ESR levels among normal subjects, which proved that yoganidra may have a significant role in controlling infection and inflammation and improving immunity. In this study, we have observed a trend of improvement of HDL and LDL levels, whereas no significant changes were observed on triglycerides and total cholesterol levels after yoganidra intervention. Less number of subjects and a short duration may be the reason for the same. The uniqueness of this pilot study is that no study in the recent past had implemented a supervised yoganidra intervention with a comparison between an experimental and a control group, weekly blood pressure monitoring, and monitoring the participants for Hs-CRP and lipid profile. Many subjects showed definite symptomatic improvement after 12 weeks of yoganidra with no side effects. We conclude that this therapy opens a new avenue in the management of hypertension. We suggest that yoganidra may be used as a stand-alone therapy for untreated/asymptomatic for early or newly diagnosed hypertensive or prehypertensive subjects that may not require any medications to manage hypertension. There are separate reports, which show that the yoganidra impacts psychological well-being, quality of life, blood sugar levels, mental health (stress, concentration, and behavior), and sleep disorders [31-35]. Overall, yoganidra can be considered as an add-on option for the prevention and control of chronic noncommunicable diseases in all age-groups, which can be regularly practiced at home, at the office, and community centers, without much financial burden. Yoganidra can be incorporated with the "Fit India" movement along with other physical exercises. Most of our population working in government and private organizations are seen to be suffering from type 2 diabetes, hypertension, dyslipidemia, depression, and stress, which affect their work efficiency, leading to financial losses not only to the individual but also to the county as well. Yoganidra can be regularly practiced after office hours, which can prevent and manage hypertension, cardiovascular events, and improve mental health status without medications. Additionally, no side effects were observed in practicing yoganidra, and this could be effectively incorporated as an indigenous novel intervention for newly diagnosed hypertensive and psychosomatics under the National Health Scheme.

\section{Conclusions}

In this pilot study, we observed a significant reduction in SBP, DBP, and MAP among the yoganidra intervention group as compared with the control group. Yoganidra, one of the components of yoga, should become an integral part of human life. The good health of people always impacts the country's economy in a positive way.

\section{Recommendations}

Keeping in view the significant findings of this study and the potential beneficial impact of yoganidra on managing HTN and related health issues, it is highly recommended to carry out multicentric randomized controlled trials with a larger sample size categorized by pharmacological groups. Other sympathetic parameters may be evaluated for a better understanding of the pathophysiology involved in reducing hypertension. Thus, the data may help us bring policy reform to address the burden of hypertension in the country.

\section{Limitations}

The small sample size is a significant limitation of this study. However, this pilot study provides significant impetus to initiate major trials to evaluate the positive effect of yoganidra on hypertension and other NCD markers.

\section{Data Availability}

The datasets for the current study are available from the corresponding author upon request.

\section{Ethical Approval}

This study was approved by the Institutional Ethical Committee, Indian Council of Medical Research-National Institute of Nutrition, Hyderabad (IEC no. 04/II/2016). Principle investigator followed the ethical principles of the Declaration of Helsinki.

\section{Consent}

Written informed consent was obtained from all the study participants.

\section{Conflicts of Interest}

The authors declare that they have no conflicts of interest. 


\section{Authors' Contributions}

Devraj JP contributed to study design, obtaining approvals, subject recruitment, analyzing results, and manuscript writing. Santosh Kumar B contributed to clinical evaluation, execution, follow-up, and manuscript corrections. Raja Sriswan M contributed to screening subjects, clinical evaluation, execution, analyzing results, and manuscript corrections. Jagdish B contributed to study design, performed execution, and followed up the study. Priya B. S contributed to subject recruitment, data collection and checking, followup, and result interpretation. Neelu S B contributed to subject recruitment, data collection and checking, follow-up, and result interpretation. Vijayabhaskar Desai Rao contributed to the design and statistical analysis. Manoj Kumar contributed to subject recruitment, laboratory investigations, result interpretation, and manuscript corrections. J J Babu Geddam contributed to overall supervision. R. Hemalatha contributed to study design, critical inputs during trial, interpretation, and manuscript correction.

\section{Acknowledgments}

The authors thank the team of "Rishi Chaitanya Ashram," NH-1 Ganaur District Sonipat, Haryana, India-131101, for logistics and financial support.

\section{Supplementary Materials}

Weekly blood pressure was recorded for experimental group subjects, and the mean and SD of both SBP and DBP are as shown in Supplementary Table S1. A gradual reduction in both SBP and DBP was observed among the intervention group. (Supplementary Materials)

\section{References}

[1] World Health Organization, "Hypertension: fact sheet," World Health Organization, Geneva, Switzerland, 2011.

[2] R. Sivasubramanian, Z. Geevar, G. Kartik, J. Shivkumar, and R. P. P. Mohanan, "Prevalence of hypertension among Indian adults: Results from the great India blood pressure survey," Indian Heart Journal, vol. 71, no. 4, pp. 309-313, 2019.

[3] E. Gakidou, A. Afshin, A. A. Abajobir, K. H. Abate, C. Abbafati, and K. M. Abbas, "Global, regional, and national comparative risk assessment of 84 behavioural, environmental and occupational, and metabolic risks or clusters of risks, 1990-2016: a systematic analysis for the global burden of disease study 2016," Lancet, vol. 16, no. 390, pp. 1345-1422, 2017.

[4] R. Anchala, N. K. Kannuri, H. Pant et al., "Hypertension in India," Journal of Hypertension, vol. 32, no. 6, pp. 1170-1177, 2014.

[5] J. He and P. K. Whelton, "Elevated systolic blood pressure and risk of cardiovascular and renal disease: overview of evidence from observational epidemiologic studies and randomized controlled trials," American Heart Journal, vol. 138, pp. 211-219, 1999.

[6] C. M. Lawes, S. Vander Hoorn, and A. Rodgers, "Global burden of blood-pressure-related disease, 2001," Lancet, vol. 371, pp. 1513-1518, 2008.
[7] M. Miller, "Dyslipidemia and cardiovascular risk: the importance of early prevention," QJM, vol. 102, no. 9, pp. 657-667, 2009.

[8] K. Chul Sung, J. Yul Suh, B. Soo Kim et al., "High sensitivity c-reactive protein as an independent risk factor for essential hypertension," American Journal of Hypertension, vol. 16, no. 6, pp. 429-433, 2003.

[9] M. Shafi Dar, A. A. Pandith, A. S. Sameer, M. Sultan, A. Yousuf, and S. Mudassar, "hs-CRP: a potential marker for hypertension in Kashmiri population," Indian Journal of Clinical Biochemistry, vol. 25, no. 2, pp. 208-212, 2010.

[10] P. Pais, D. Y. Kamath, D. Xavier, and A. Sigamani, "High sensitivity C-reactive protein (hsCRP) \& cardiovascular disease: an Indian perspective," Indian Journal of Medical Research, vol. 142, no. 1, p. 261, 2015.

[11] C. Monik, S. M. Jimenez, K. M. Rexrode et al., “Association between high-sensitivity C-reactive protein and total stroke by hypertensive status among men," Journal of American Heart Association, vol. 4, no. 9, Article ID e002073, 2015.

[12] L. E. Bautista, L. M. Vera-Cala, C. Colombo et al., "Symptoms of depression and anxiety and adherence to antihypertensive medication," American Journal of Hypertension, vol. 25, no. 4, pp. 505-511, 2012.

[13] B. Vrijens, G. Vincze, P. Kristanto, J. Urquhart, and M. Burnier, "Adherence to prescribed antihypertensive drug treatments: longitudinal study of electronically compiled dosing histories," BMJ, vol. 336, no. 7653, pp. 1114-1117, 2008.

[14] S. A. Cooper, A. Whaley-Connell, J. Habibi et al., "Reninangiotensin-aldosterone system and oxidative stress in cardiovascular insulin resistance," American Journal of Physiology-Heart and Circulatory Physiology, vol. 293, no. 4, pp. H2009-H2023, 2007.

[15] S. G. Morgan and L. Yan, "Persistence with hypertension treatment among community-dwelling $\mathrm{BC}$ seniors," The Canadian Journal of Clinical Pharmacology, vol. 11, pp. 267-273, 2004.

[16] Y. S. Liou, T. Ma, L. Tien, C. Chien, P. Chou, and G. P. Jong, "Long-term effects of antihypertensive drugs on the risk of new-onset diabetes in elderly Taiwanese hypertensives," International Heart Journal, vol. 49, no. 2, pp. 205-211, 2008.

[17] C. I. Li, J. R. Daling, M.-T. C. Tang, K. L. Haugen, P. L. Porter, and K. E. Malone, "Use of antihypertensive medications and breast cancer risk among women aged 55 to 74 years," JAMA Internal Medicine, vol. 173, no. 17, p. 1629, 2013.

[18] G.-P. Jong, H.-Y. Chen, S.-Y. Li, and Y.-s. Liou, "Long-term effect of antihypertensive drugs on the risk of new-onset atrial fibrillation: a longitudinal cohort study," Hypertension Research, vol. 37, no. 10, pp. 950-953, 2014.

[19] I. A. Kretchy, F. T. Owusu-Daaku, and S. A. Danquah, "Mental health in hypertension: assessing symptoms of anxiety, depression and stress on anti-hypertensive medication adherence," International Journal of Mental Health Systems, vol. 8, p. 25, 2014.

[20] N. Jarari, N. Rao, J. R. Peela et al., "A review on prescribing patterns of antihypertensive drugs," Clinical Hypertension, vol. 22, no. 1, p. 7, 2016.

[21] J. A. Halbert, C. Silagy, P. Finucane, R. Withers, P. Hamdorf, and G. Andrews, "The effectiveness of exercise training in lowering blood pressure: a meta-analysis of randomised controlled trials of 4 weeks or longer," Journal of Human Hypertension, vol. 11, no. 10, pp. 641-649, 1997.

[22] R. H. Fagard, "Effects of exercise, diet and their combination on blood pressure," Journal of Human Hypertension, vol. 19, pp. 20-24, 2004. 
[23] K. Kumar, "Effect of yoga nidra on hypertension and other psychological co-relates," Yoga the science Journal, vol. 3, no. 7, pp. 26-38, 2005.

[24] T. Deepa, G. Sethu, and N. Thirrunavukkarasu, "Effect of yoga and meditation on mild to moderate essential hypertensives," Journal of Clinical and Diagnostic Research, vol. 6, no. 1, pp. 21-26, 2012.

[25] S. Devi and S. Kala, "Role of yoga-nidra and shirodhara on hypertensive patients," International Journal of Yoga and Allied Sciences, vol. 4, no. 1, 2015.

[26] S. S. Saraswati, Yoga Nidra, Bihar School of Yoga, Bihar, India, 1976.

[27] T. A. Pearson, G. A. Mensah, R. W. Alexander et al., "Markers of inflammation and cardiovascular disease," Circulation, vol. 107, no. 3, pp. 499-511, 2003.

[28] W. T. Friedewald, R. I. Levy, and D. S. Fredrickson, "Estimation of the concentration of low-density lipoprotein cholesterol in plasma, without use of the preparative ultracentrifuge," Clinical Chemistry, vol. 18, no. 6, pp. 499-502, 1972.

[29] D. Ettehad, C. A. Emdin, A. Kiran et al., "Blood pressure lowering for prevention of cardiovascular disease and death: a systematic review and meta-analysis," The Lancet, vol. 387, no. 10022, pp. 957-967, 2016.

[30] R. Gordan, J. K. Gwathmey, and L.-H. Xie, "Autonomic and endocrine control of cardiovascular function," World Journal of Cardiology, vol. 7, no. 4, pp. 204-214, 2015.

[31] L. R. Bali, "Long-term effect of relaxation on blood pressure and anxiety levels of essential hypertensive males: a controlled study," Psychosomatic Medicine, vol. 41, no. 8, pp. 637-46, 1979.

[32] D. Kumar and R. Singh, "Effects of selected yogic practices on blood pressure among school boys," Anthropological Bulletin, vol. 9, no. 2, pp. 13-18, 2017.

[33] R. C. Tripathi, "Effects of yoga nidra on physical and psychological health," in Venture into cross-cultural psychology: Proceedings from the $23^{\text {rd }}$ Congress of the International Association for Cross-Cultural Psychology, M. Karasawa, M. Yuki, K. Ishii, Y. Uchida, K. Sato, and W. Friedlmeier, Eds., Publications of HSE, Nagoya, Japan, 2018.

[34] T. Fuela Esther and A. Dhivya Bharathi, "Effect of yoga-nidra on blood pressure among elderly with hypertension residing at selected old age homes, Coimbatore," International Journal of Nursing Education and Research, vol. 7, no. 1, pp. 30-32, 2019.

[35] K. Kumar and P. Pandya, "A study on the impact on ESR level through yogic relaxation technique, yoga nidra," Indian Journal of Traditional knowledge, vol. 11, no. 2, pp. 358-361, 2012. 